\title{
Melanocortins induce interleukin 6 gene expression and secretion through melanocortin receptors 2 and 5 in 3T3-L1 adipocytes
}

\author{
Dong-Jae Jun*, Kyung-Yoon Na*, Wanil Kim, Dongoh Kwak, Eun-Jeong Kwon, \\ Jong Hyuk Yoon, Kyungmoo Yea, Hyeongji Lee, Jaeyoon Kim, Pann-Gill Suh, \\ Sung Ho Ryu and Kyong-Tai Kim
}

Division of Molecular and Life Science, Department of Life Science, Pohang University of Science and Technology (POSTECH), San 31, Hyoja Dong,

Pohang 790-784, Republic of Korea

(Correspondence should be addressed to K-T Kim; Email: ktk@postech.ac.kr)

*(D-J Jun and K-Y Na contributed equally to this work)

\begin{abstract}
Interleukin 6 (IL6) is a pleiotropic cytokine that not only affects the immune system, but also plays an active role in many physiological events in various organs. Notably, $35 \%$ of systemic IL6 originates from adipose tissues under noninflammatory conditions. Here, we describe a previously unknown function of melanocortins in regulating $1 / 6$ gene expression and production in 3T3-L1 adipocytes through membrane receptors which are called melanocortin receptors (MCRs). Of the five MCRs that have been cloned, MC2R and MC5R are expressed during adipocyte differentiation. $\alpha$-Melanocyte-stimulating hormone $(\alpha-\mathrm{MSH})$ or ACTH treatment of 3T3-L1 adipocytes induces $/ / 6$ gene expression and production in a time- and concentration-dependent manner via various signaling pathways including the protein kinase $A$, p38 mitogen-activated protein kinase, cJun N-terminal kinase, and IKB kinase pathways. Specific inhibition of MC2R and MC5R expression with short interfering Mc2r and Mc5r RNAs significantly attenuated the $\alpha-\mathrm{MSH}$-induced increase of intracellular cAMP and both the level of $I / 6$ mRNA and secretion of IL6 in 3T3-L1 adipocytes. Finally, when injected into mouse tail vein, $\alpha-\mathrm{MSH}$ dramatically increased the $/ / 6$ transcript levels in epididymal fat pads. These results suggest that $\alpha-\mathrm{MSH}$ in addition to ACTH may function as a regulator of inflammation by regulating cytokine production.
\end{abstract}

Journal of Molecular Endocrinology (2010) 44, 225-236

\section{Introduction}

Interleukin 6 (IL6) is a pleiotropic cytokine involved in the regulation of the immune response, acute-phase reaction, nervous and endocrine system function, bone metabolism, hematopoiesis, insulin resistance, and various human diseases (Kamimura et al. 2003). Notably, adipose tissue has been regarded as a major source of circulating IL6, particularly in obesity, because $35 \%$ of systemic IL6 originates from subcutaneous adipocytes (Mohamed-Ali et al. 1997, Fried et al. 1998). Recent studies have demonstrated that Il6 negatively affects insulin signaling in adipocytes by reducing expression of insulin receptor signaling components (Rotter et al. 2003), by inducing the suppressor of cytokine signaling 3 (a negative regulator of insulin signaling; Lagathu et al. 2003, Shi et al. 2004), and by decreasing adiponectin secretion (Fasshauer et al. 2003, Kristiansen \& Mandrup-Poulsen 2005). Many IL6 inducers are known including IL1 $\beta$, tumor necrosis factor- $\alpha$, lysophosphatidic acid, prostaglandin E, thyroid-stimulating hormone, platelet-derived growth factor, catecholamine, palmitate, bacterial lipopolysaccharide (LPS), and viral infection and associated transforming growth factor- $\beta$ (Verhasselt et al. 1997, Franchimont et al. 1999, Legrand-Poels et al. 2000, Fang et al. 2004, Ajuwon \& Spurlock 2005, Liu et al. 2005, Tan et al. 2007, Antunes et al. 2008, Diya et al. 2008). This is the first time that melanocortins induce $I l 6$ gene expression and production through the MCRs.

Melanocortins are generated by the proteolytic cleavage of the precursor molecule, proopiomelanocortin (POMC). Differential enzymatic cleavage of POMC by prohormone convertases results in the production of ACTH, $\alpha$-melanocyte-stimulating hormone $(\alpha-\mathrm{MSH}), \beta-\mathrm{MSH}, \gamma-\mathrm{MSH}$, and other hormones. Even though these hormones are derived from different regions of the precursor POMC, because they share a core binding sequence His-Phe-Arg-Trp (HFRW), which is required for binding and activation of the receptors, ACTH can activate all five MCRs, whereas $\alpha$-MSH can activate all MCRs except MC2R (Yang \& Harmon 2003). $\alpha$-MSH is one of the POMC 
derivatives, as N-terminal region of ACTH. It seems like $\alpha$-MSH has a function that is similar to that of ACTH. Melanocortins are recognized as pivotal components of the hypothalamic-pituitary-adrenal (HPA) axis in mediating response to stress. It has been postulated that stress may be a causal factor in metabolic syndromes such as insulin resistance, type 2 diabetes, and hypertension via perturbation of the HPA axis (Gohil et al. 2001, Kaufman et al. 2007). The pituitary gland secretes critical hormones which affect many target tissues in our body. On the other hand, adipocyte tissue expresses receptors for many hormones including pituitary hormones, and secretes several factors which are called adipotropins (Schaffler et al. 2006). So, adipocyte tissue is not a passive organ any longer, and this is called hypothalamic-pituitary-adipose axis. To date, five MCRs have been described (MC1R-MC5R). All are coupled to stimulatory G-proteins (Gs), which after binding to melanocortins initiate the activation of adenylyl cyclase, ultimately resulting in the transcription of cAMP-responsive genes (Bohm et al. 2006). MC1R and MC2R have classically been considered to have a role in the skin pigmentation (Schaffler et al. 2006) and adrenal steroidogenesis respectively (Cone 2006). MC3R and MC4R are expressed primarily in the hypothalamus of the central nervous system (CNS). The best characterized effects of MC3R and MC4R are in the control of food intake, energy expenditure, and sexual function (Wikberg \& Mutulis 2008), and disruption of $M c 4 r$ gene has been shown to cause obesity in mice (Butler et al. 2001). Among the five subtypes of MCRs, MC5R is a relatively ubiquitous receptor in peripheral tissues, suggesting a direct peripheral action for melanocortins. MC5R participates in the control of exocrine secretions in exocrine glands and fatty acid oxidation in skeletal muscle (Chen et al. 1997, An et al. 2007).

The melanocortin peptides ACTH, $\alpha-\mathrm{MSH}$, and $\beta$-lipotropin have long been recognized to have different degrees of lipolytic activity in the adipocytes of various mammalian species (Boston 1999). ACTH has recently been shown to inhibit leptin production in 3T3-L1 adipocytes (Norman et al. 2003) and to promote a pro-inflammatory adipocytokine profile (Iwen et al. 2008). However, the peripheral effects of $\alpha-\mathrm{MSH}$ and MCRs in adipocytes have not been extensively investigated. In this study, we demonstrate for the first time that melanocortins are inducers of $I l 6$ in 3T3-L1 adipocytes. We show that MC5R mediates the $\alpha-\mathrm{MSH}-$ induced increase in $1 l 6$ gene expression, and that MC2R mediates the ACTH-induced increase in $I l 6$ gene expression via the activation of the protein kinase A (PKA), p38 mitogen-activated protein kinase (MAPK), cJun N-terminal kinase (JNK), and I $\kappa$ B kinase (IKK) signaling pathways.

\section{Materials and methods}

\section{T3-L1 cell cultures}

3T3-L1 cells were grown in DMEM containing $1 \%$ penicillin/streptomycin $(\mathrm{P} / \mathrm{S})$ and $10 \%$ fetal bovine serum (FBS) until they reach confluency. They were then differentiated with the differentiation mixture (DMEM containing $1 \% \mathrm{P} / \mathrm{S}$ and $10 \% \mathrm{FBS}, 500 \mu \mathrm{M}$ 3-isobutyl-1-methylxanthine, $10 \mu \mathrm{g} / \mathrm{ml}$ insulin, and $1 \mu \mathrm{M}$ dexamethasone) for 2 days as described (Jun et al. 2006). Insulin was present for an additional 4 days, and then, the culture medium was changed with only DMEM $(1 \% \mathrm{P} / \mathrm{S}$ and $10 \% \mathrm{FBS})$ for 2 days. Each medium was changed every 2 days.

\section{RNA extraction and real-time quantitative reverse transcription-PCR}

Total RNA was extracted from differentiated adipocytes using TRIzol reagent (Invitrogen) according to the manufacturer's protocol. For real-time quantitative reverse transcription (RT)-PCR, total RNA was reversely transcribed using an ImProm-II RT system (Promega) according to the manufacturer's instructions. For detection and quantification, a MyiQ real-time PCR detection system (Bio-Rad) was used. PCRs were performed using a SYBR Premix Ex Taq II (Takara, Seoul, Republic of Korea). PCRs were carried out in a final volume of $20 \mu \mathrm{l}$ using $0.5 \mu \mathrm{M}$ of each primer, cDNA, and $10 \mu \mathrm{l}$ of the supplied enzyme mixture containing the DNA doublestrand-specific SYBR Green I dye for detection of PCR products. PCRs were performed with a 3-min preincubation at $95^{\circ} \mathrm{C}$ followed by 40 cycles of $15 \mathrm{~s}$ at $95^{\circ} \mathrm{C}$ and $30 \mathrm{~s}$ at $60^{\circ} \mathrm{C}$. PCR products were verified by melting curve analysis, agarose gel electrophoresis, and DNA sequencing.

The following primers were used:

Arbp (forward, 5'-AAAACTCCGGTCTGGATTTATTTAG; reverse, $5^{\prime}$-TAATTCACACCTGGAAAATCTTTGT), Gapdh (forward, 5'-GCCATCAATGACCCCTTCATT; reverse, $5^{\prime}$-GCTCCTGGAAGATGGTGATGG), Add1 (forward, $5^{\prime}$-CATCTGTTGTAAGGTGTATTTGCTG; reverse, $5^{\prime}$-AGATGACTAGGGAACTGTGTGTGTT), PPAR $\gamma$ (forward, $5^{\prime}$-TTGCTGAACGTGAAGCCCATCGAGG; reverse, 5'-GTCCTTGTAGATCTCCTGGAGCAG),

C/EBPa (forward, 5'-CCATTTTATTTGGTCTTTTGTTTTG; reverse, 5'-CTACATACACCCTTGGACAACTAGG),

Pref1 (forward, 5'-CATGAAAGAGCTCAACAAGAGTACC; reverse, $5^{\prime}$-GTTATACTGCAACAGGAGGTTCTTC), Pail (forward, 5'-CCTGGTCAACCACCTTAGTTAGATA; reverse, 5'-AAATCAGAGAGAAAGAGGGAGAGAG), 
aP2 (forward, 5'-ACAATAAAGAGAAAACGAGATGGTG; reverse, $5^{\prime}$-TGCTTGCTTATTAGTGGAAAATCAT), $M c 1 r$ (forward, $5^{\prime}$-GATTTGGGAATTAGACAAGACCTTT; reverse, 5'-GGACAAAGAAGTGTTCAGTACCAGT),

$M c 2 r$ (forward, $5^{\prime}$-TAAAGGGACCAAATAACACATCAGT; reverse, $5^{\prime}$-CTTTCCTGTTTAGCACAACATTTC), $M c 3 r$ (forward, $5^{\prime}$-ATATTCTGTGGGAGATTGAGTGAAG; reverse, 5'-CCAACAATAATAACAACCATGACAA), $M c 4 r$ (forward, $5^{\prime}$-TAAGTTTGTGACTTTTGACATGGAA; reverse, 5'-TGGAACCTTGATAAATAACAGGAAA),

$M c 5 r$ (forward, 5'-GTAAACAGAAGATTCAACTCCCAGA; reverse, 5'-CGTTCAGGGTAAGATTCAATACAGT),

Rbp4 (forward, 5'-GACAGCTACTCCTTTGTGTTTTCTC; reverse 5'-AGAAATCTTCAAACTTCACATCCT), Igf1 (forward, 5'-GGAAAGGAAGTACATTTGAAGAACA; reverse, 5'-TTATTTGGTAGGTGTTTCGATGTTT),

Igf2 (forward, 5'-AAAAACAATTGGCAAAATCAAATAA; reverse, $5^{\prime}$-TTACACTAAAGGTGCTTGGATAAGG), Il6 (forward, 5'-AGGCTTAATTACACATGTTCTCTGG; reverse, 5'-TTATATCCAGTTTGGTAGCATCCAT),

adiponectin (forward, 5'-GTTCTCTTCACCTACGACCAGTATC; reverse, 5'-AAAGCCAGTAAATGTAGAGTCGTTG),

resistin (forward, 5' -ACTGACAAGAAGATCAAACAAGACT; reverse, 5'-AGTGACACACTTTTTCTTCACGAAT), and

Tnf $\alpha$ (forward, 5'-GATTTGCTATCTCATACCAGGAGAA; reverse, 5'-AAGTCTAAGTACTTGGGCAGATTGA).

Relative value of gene expression was analyzed using the $2 C_{(\mathrm{t})}$ method (Livak \& Schmittgen 2001).

\section{Western blot analysis}

3T3-L1 adipocytes were plated in 60-mm tissue culture dishes and treated with melanocortins for various time periods. After treatment, the cells were washed twice with cold PBS and then lysed with lysis buffer $(250 \mathrm{mM}$ Tris-Cl (pH 6.5), 2\% SDS, 4\% $\beta$-mercaptoethanol, $0.02 \%$ bromophenol blue, and $10 \%$ glycerol). Equal amounts of whole cell lysates were resolved by $12 \cdot 5 \%$ SDS-PAGE and transferred to a polyvinylidene difluoride membrane. Membranes were blocked using Tris-buffered saline with Tween 20 (TTBS, $150 \mathrm{mM}$ $\mathrm{NaCl}, 10 \mathrm{mM}$ Tris-HCl, $\mathrm{pH} 8 \cdot 0$, and $0 \cdot 05 \%$ Tween 20 ) containing $5 \%$ skimmed milk for $30 \mathrm{~min}$, and were then incubated overnight with the indicated primary antibody. After washing three times with TTBS, the membranes were probed with HRP-conjugated secondary antibody to allow for the detection of the appropriate bands using an ECL detection system (Neuronex Co., Daegu, Republic of Korea).

\section{Measurement of $\left[{ }^{3} \mathrm{H}\right]$ cAMP}

Intracellular cAMP generation was determined by $\left[{ }^{3} \mathrm{H}\right]$ cAMP competition assay in binding to cAMP-binding protein as described previously by Jun et al. (2006) with some modifications. To determine the cAMP production induced by melanocortins, the 3T3-L1 adipocytes were stimulated with agonists for $20 \mathrm{~min}$ in the presence of the phosphodiesterase inhibitor Ro 20-1724 $(5 \mu \mathrm{M})$, and the reaction was quickly terminated by three repeated cycles of freezing and thawing. The samples were then centrifuged at $12000 \mathrm{~g}$ for $5 \mathrm{~min}$ at $4{ }^{\circ} \mathrm{C}$. The cAMP assay is based on the competition between $\left[{ }^{3} \mathrm{H}\right]$-labeled cAMP and unlabeled cAMP present in the sample for binding to a crude cAMPbinding protein prepared from bovine adrenal cortex according to the method of Brown et al. (1971). Bound $\left[{ }^{3} \mathrm{H}\right]$ cAMP in the supernatant was then determined by liquid scintillation counting. Each sample was incubated with $50 \mu \mathrm{l}\left[{ }^{3} \mathrm{H}\right]$-labeled cAMP $(5 \mu \mathrm{Ci})$ and $100 \mu \mathrm{l}$ binding protein for $2 \mathrm{~h}$ at $4{ }^{\circ} \mathrm{C}$. Separation of proteinbound cAMP from unbound cAMP was achieved by absorption of free cAMP onto charcoal $(100 \mu \mathrm{l})$, followed by centrifugation at $12000 \mathrm{~g}$ at $4{ }^{\circ} \mathrm{C}$. The $200-$ $\mu \mathrm{l}$ supernatant was then placed into an Eppendorf tube containing $1.2 \mathrm{ml}$ scintillation cocktail to measure radioactivity. The cAMP concentration in the sample was determined based on a standard curve and expressed as picomoles per microgram of protein.

\section{ELISA}

Medium from differentiated 3T3-L1 cells cultured in 24-well plates was analyzed for IL6 using a kit (R\&D systems, Minneapolis, MN, USA).

\section{RNA interference and transfection}

The siRNA SMART pool containing $50 \mathrm{nmol}$ of a mixture of four oligonucleotides which target mouse $\mathrm{Mc} 2 \mathrm{r}$ and Mc $5 r$ mRNA destruction by RISCs was purchased from Dharmacon, Inc (Lafayette, CO, USA). Transfection of the 3T3-L1 adipocytes with the siRNA SMART pool oligonucleotides was carried out with a microporator (Digital Biotechnology, Daegu, Republic of Korea) according to the protocol provided by the company.

\section{Animal experiment}

Eight-week-old C57BL/6J male mice were obtained from the Orient Bio (Sungnam, South Korea). All the mouse experiments were performed in the animal facility 
under POSTECH institutional guidelines. The mice were kept in individual cages in a room in which lighting was controlled (12 $\mathrm{h}$ light: $12 \mathrm{~h}$ darkness), and the temperature was maintained at $23^{\circ} \mathrm{C}$. Mice were sacrificed by cervical dislocation $0,1,3$, and $6 \mathrm{~h}$ after injecting vehicle or $1 \mathrm{mg} / \mathrm{kg}$ of $\alpha$-MSH i.v. Immediately after the mice were sacrificed, epididymal fat pads were removed. Total RNA was extracted from epididymal fat pads using TRIzol reagent (Invitrogen) according to the manufacturer's protocol, and then $I l 6$ transcript levels were measured using a real-time quantitative RT-PCR.

\section{Materials}

$\alpha-, \beta-$, and $\gamma-\mathrm{MSH}, \mathrm{SB} 203580$, SP600125, Bay11-7085, H89, 6-Bnz-cAMP, forskolin, isoproterenol, and LPS were purchased from the Sigma-Aldrich Inc. ACTH was purchased from Phoenix Pharmaceuticals Company Inc. (Burlingame, CA, USA).

\section{Statistical analysis}

All numerical values are given as mean \pm s.D. Significance of differences between mean values of two groups was evaluated using Student's $t$-test for unpaired data as appropriate. A probability of $P<0.001$ or $P<0.05$ was considered significant.

\section{Results}

\section{MCR subtypes are expressed in metabolic tissues and 3T3-L1 adipocytes}

To investigate the expression of the five MCR subtypes in mouse metabolic tissues and 3T3-L1 adipocytes, realtime quantitative RT-PCR was carried out using primers specific for each subtype. Both MC2R and MC5R were the two most abundant MCRs in all adipose tissues (subcutaneous, retroperitoneal, and epididymal fat), and the patterns of MCR expression in 3T3-L1
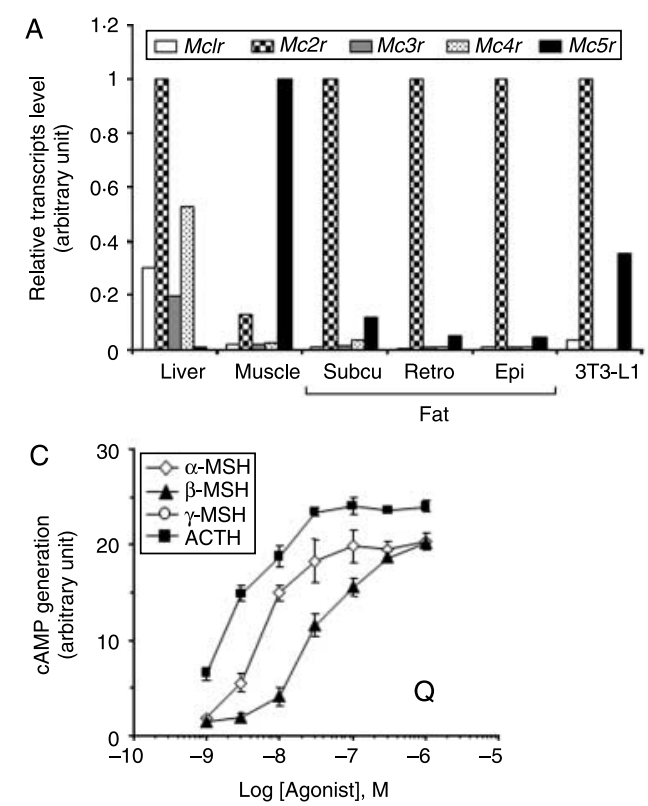

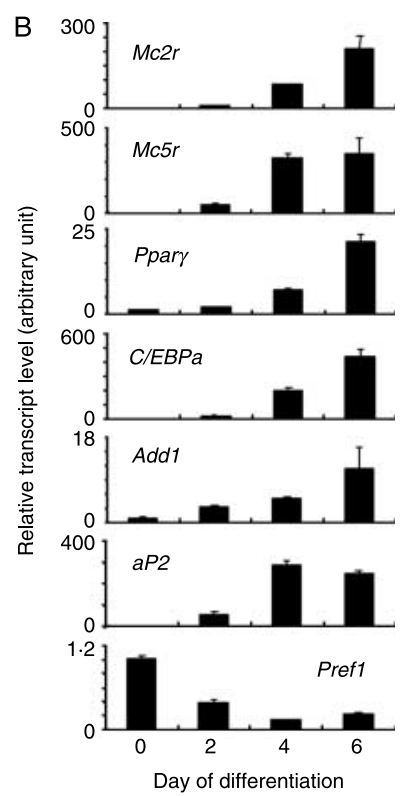

Figure 1 Functional expression of melanocortin receptor subtypes in mouse tissues and 3T3-L1 adipocytes. (A) Real-time quantitative RT-PCR analysis of melanocortin receptor subtypes in mouse metabolic tissues and 3T3-L1 adipocytes. Detection of mRNA corresponding to all five Mcrs in liver, muscle, subcutaneous fat, retroperitoneal fat, epididymal fat, and 3T3-L1 adipocytes. (B) Real-time quantitative RT-PCR analysis of $\mathrm{Mc2} r$ and $\mathrm{Mc5} r$ during adipogenesis. The CDNAs derived from the 3T3-L1 cells which had undergone differentiation for various time periods were amplified using specific primers. For comparison, five differentiation-specific genes were also analyzed: PPAR $\gamma$, $C / E B P a, A d d 1, a P 2$, and Pref1. The relative expression of the transcripts was normalized to acidic ribosomal phosphoprotein PO (Arbp) mRNA levels, and values represent the mean \pm s.D. (C) Concentration-dependent effects of melanocortins on cAMP generation. 3T3-L1 adipocytes were treated with various concentrations of $\alpha-\mathrm{MSH}, \beta-\mathrm{MSH}, \gamma-\mathrm{MSH}$, or ACTH for $20 \mathrm{~min}$, and then cAMP production was measured. The data present the means \pm S.D. of triplicate samples. Each experiment was performed independently at least three times. 
adipocytes were similar to those of adipose tissues (Fig. 1A). Next, we investigated whether the levels of $M c 2 r$ and $M c 5 r$ were changed during adipocyte differentiation. Levels of individual transcripts were analyzed by real-time quantitative RT-PCR during the time course of 3T3-L1 differentiation up to 6 days post induction. The kinetics of $\mathrm{Mcr}$ mRNA expression were compared to those of several markers of adipogenesis, including the transcription factors peroxisome proliferator-activated receptor $\gamma(P P A R \gamma)$, CAAT/ enhancer-binding protein $\alpha(C / E B P a)$, and adipocyte determination differentiation factor $1(A d d 1)$, as well as adipose lipid-binding protein $(a P 2)$. We also assayed the kinetics of the expression of the preadipocyte marker, preadipocyte factor 1 (Pref1; Fig. 1B). These data indicate that adipogenesis is accompanied by the upregulation of $M c 2 r$ and $M c 5 r$ mRNAs. MCRs are G-protein-coupled receptors and are coupled to adenylyl cyclase via Gs (Cone 2006). Because mRNA expression is not necessarily correlated with protein expression or activity, the capacities of the melanocortins to stimulate cAMP production were compared in order to characterize their pharmacological properties in 3T3-L1 adipocytes. As shown in Fig. 1C, ACTH was most active in elevating the level of intracellular cAMP followed by $\alpha-\mathrm{MSH}, \beta-\mathrm{MSH}$, and $\gamma-\mathrm{MSH}$. This is consistent with the properties of the MC2R subtype, which is selective for ACTH, and of the MC5R subtype, which binds preferentially to $\alpha$-MSH, with equal affinity to $\beta$-MSH and ACTH, and with lowest affinity to $\gamma-\mathrm{MSH}$ (Cone 2006). So, $\alpha$-MSH is the most potent activator of MC5R. These data suggest that MC2R and MC5R are functionally active in 3T3-L1 adipocytes.

\section{Melanocortins induce $1 / 6$ expression in 3T3-L1 adipocytes}

We examined the effect of $\alpha-\mathrm{MSH}$ and ACTH on the level of adipocytokines in 3T3-L1 adipocytes. Of the adipocytokines tested, only IL6 was induced by
A

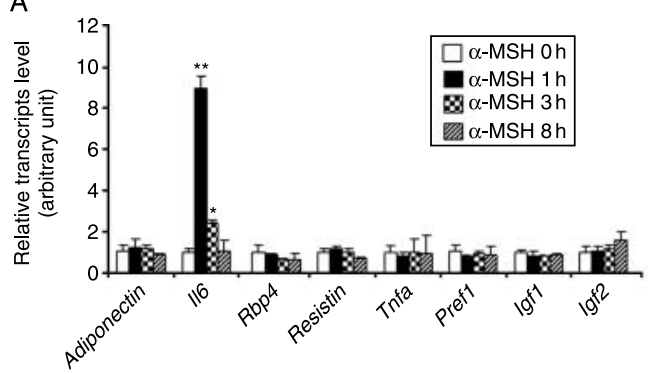

B

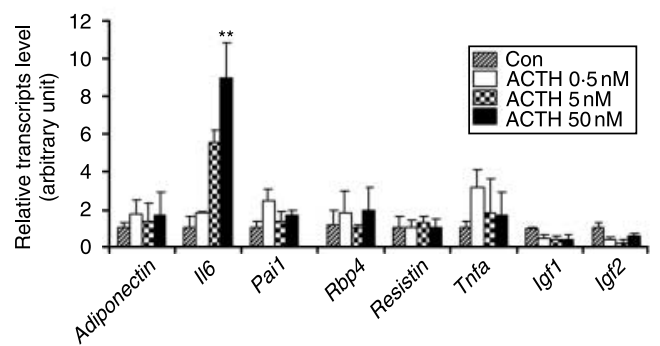

C
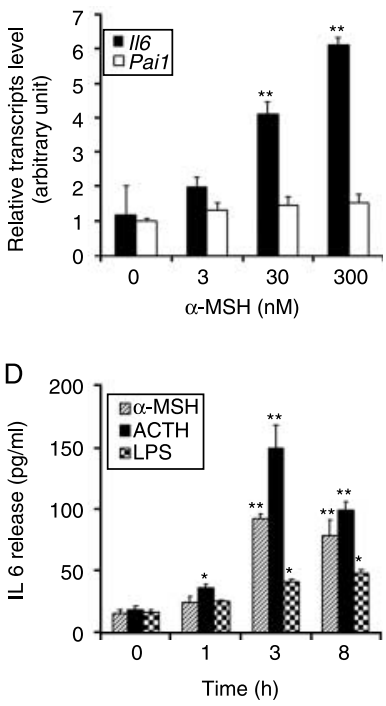

Figure 2 Melanocortins increase $1 / 6$ gene expression and secretion. (A) Differentiated 3T3-L1 adipocytes were incubated with $\alpha-\mathrm{MSH}(300 \mathrm{nM})$ for $0,1,3$, and $8 \mathrm{~h}$, and various adipocytokines including adiponectin, II6, Rbp4, resistin, Tnfa, Pref1, Igf1, and Igf2 mRNA levels were analyzed with real-time quantitative RT-PCR using Gapdh as a reference. Values represent the mean \pm S.D. of triplicate samples. (B) Differentiated 3T3-L1 adipocytes were incubated with various concentrations of ACTH. After $1 \mathrm{~h}$, the cells were harvested, and various adipocytokines including adiponectin, I/6, Pai1, Rbp4, resistin, Tnfa, Igf1, and Igf2 mRNA levels were analyzed with real-time quantitative RT-PCR using Gapdh as a reference. (C) Differentiated 3T3-L1 adipocytes were stimulated with various concentrations of $\alpha-\mathrm{MSH}$. After $1 \mathrm{~h}$, the cells were harvested, and 116 and Pai1 mRNA levels were determined using real-time quantitative RT-PCR. (D) 3T3-L1 adipocytes were stimulated with $\alpha-\mathrm{MSH}(300 \mathrm{nM})$, ACTH $(50 \mathrm{nM})$, and LPS $(1 \mu \mathrm{g} / \mathrm{ml})$ for 1,3 , and $8 \mathrm{~h}$. The supernatants were collected, and IL6 concentrations were determined by ELISA. Values represent the means \pm s.D. of triplicate samples. ${ }^{\star} P<0.05 ;{ }^{* \star} P<0.001$ compared with the zero time point. Each experiment was performed independently at least three times. 
treatment with $\alpha$-MSH (Fig. 2A) or ACTH (Fig. 2B). Levels of $I l 6$ mRNA were elevated within $1 \mathrm{~h}$ of $\alpha$-MSH treatment and returned to baseline level by $3 \mathrm{~h}$, as determined by real-time quantitative RT-PCR (Fig. 2A). Dramatic increase of $I l 6$ mRNA was observed when $50 \mathrm{nM}$ ACTH was administered (Fig. 2B). $\alpha$-MSH at a concentration of $3-300 \mathrm{nM}$ induced $I l 6$ gene expression in a concentration-dependent manner, but it did not induce the expression of Pail (negative control; Fig. 2C). In agreement with this finding, the level of IL6 protein secreted into the culture medium of 3T3-L1 adipocytes increased steadily after $\alpha$-MSH or ACTH addition, and peaked at $\sim 3 \mathrm{~h}$ as determined by IL6 ELISA (Fig. 2D). ACTH increased $I l 6$ gene expression to higher levels than seen for $\alpha-\mathrm{MSH}$, but the profile of the time course was similar to that of $\alpha$-MSH. LPS was included in the assay as a positive control. No further increase in the level of IL6 was detected when the experiment was extended to $24 \mathrm{~h}$ (data not shown), indicating that maximal IL6 protein production was attained by $3 \mathrm{~h}$. Taken together, these data suggest that melanocortins function as inducers of Il6 expression in 3T3-L1 adipocytes.
PKA, p38 MAPK, JNK, and IKK signaling pathways are involved in the melanocortin-mediated increase in $1 / 6$ gene expression and secretion

It has been reported that several stimuli including proinflammatory cytokines, $\beta_{2}$-adrenergic receptor agonists, and adiponectin induce IL6 production through the p38 MAPK, PKA, and NFKB signaling pathways in various tissues and cells (Legrand-Poels et al. 2000, Tang et al. 2007). Therefore, we investigated the possibility that these mediators are also involved in the signal transduction pathway leading to increased IL6 production in $\alpha$-MSH-treated 3T3-L1 adipocytes. Pretreatment of cells with either the p38-specific inhibitor SB203580 or the IKK inhibitor Bay11-7082 for $30 \mathrm{~min}$ prior to $\alpha$-MSH treatment attenuated $\alpha$-MSH-induced $I l 6$ production, whereas the JNK inhibitor SP600125 markedly potentiated $\alpha$-MSHinduced $I l 6$ production (Fig. 3A-C). The results suggest that p38 MAPK and IKK signaling pathways activate $\alpha$-MSH-induced $I l 6$ gene expression, but JNK signaling pathway inhibits $\alpha$-MSH-induced $I l 6$ gene expression. Western blot analysis revealed that $\alpha$-MSH stimulation
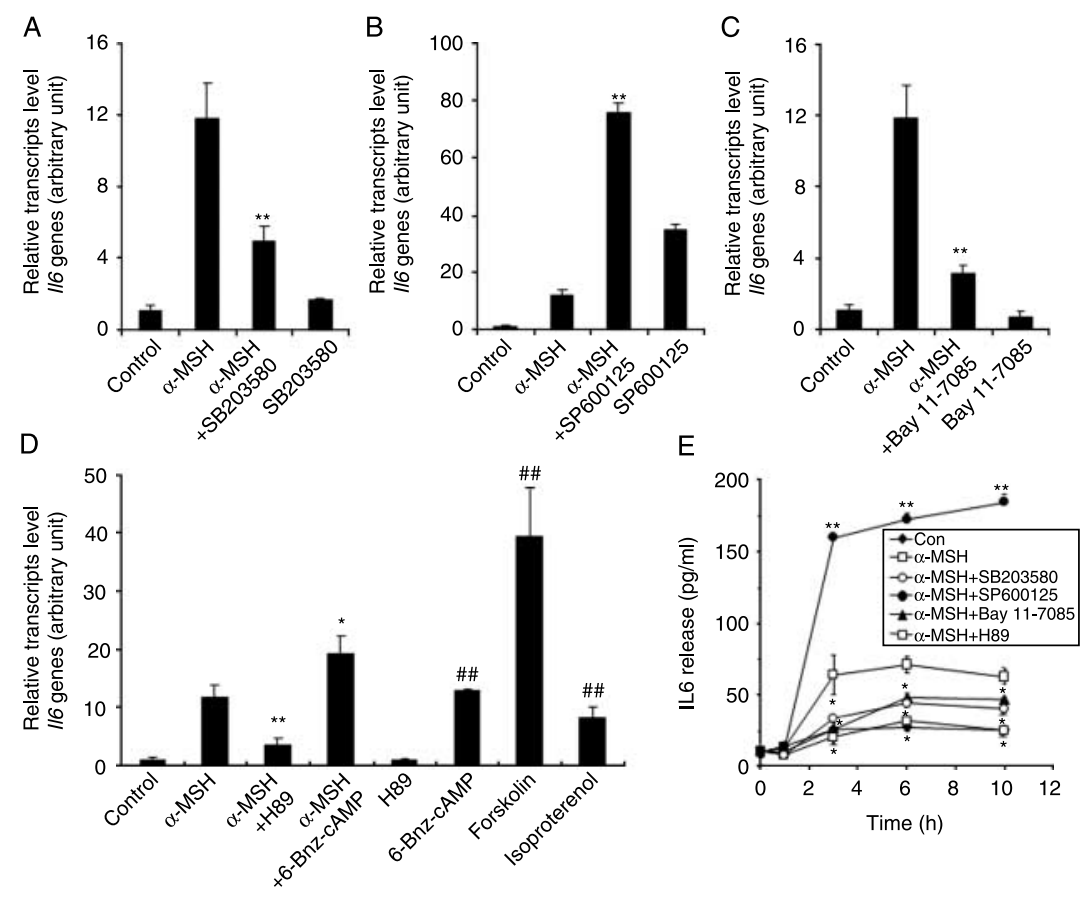

Figure 3 PKA, p38 MAPK, JNK, and IKK are involved in $\alpha-\mathrm{MSH}$-induced $/ / 6$ gene expression and secretion. Differentiated $3 T 3-L 1$ adipocytes were pretreated with $A$, SB203580 $(10 \mu \mathrm{M})$; B, SP600125 $(10 \mu \mathrm{M})$; C, Bay 11-7085 $(10 \mu \mathrm{M})$; and D, H89 $(1 \mu \mathrm{M})$ and 6-Bnz-cAMP $(50 \mu \mathrm{M})$ for 30 min prior to treatment with $\alpha-\mathrm{MSH}(300 \mathrm{nM})$ for $1 \mathrm{~h}$. (D) 3T3-L1 adipocytes were also treated with forskolin $(3 \mu \mathrm{M})$, and isoproterenol $(3 \mu \mathrm{M})$ alone for $1 \mathrm{~h}$. (E) In the presence of each inhibitor, cells were treated with $\alpha$-MSH for indicated time intervals, and culture medium was collected to measure secreted IL6. Data represent the means \pm S.D. of triplicate samples. ${ }^{\star} P<0.05$; ${ }^{\star \star} P<0.001$ compared with the $\alpha$-MSH-treated group. ${ }^{\#} P<0.001$ compared with the control group. Each experiment was performed independently at least three times. 


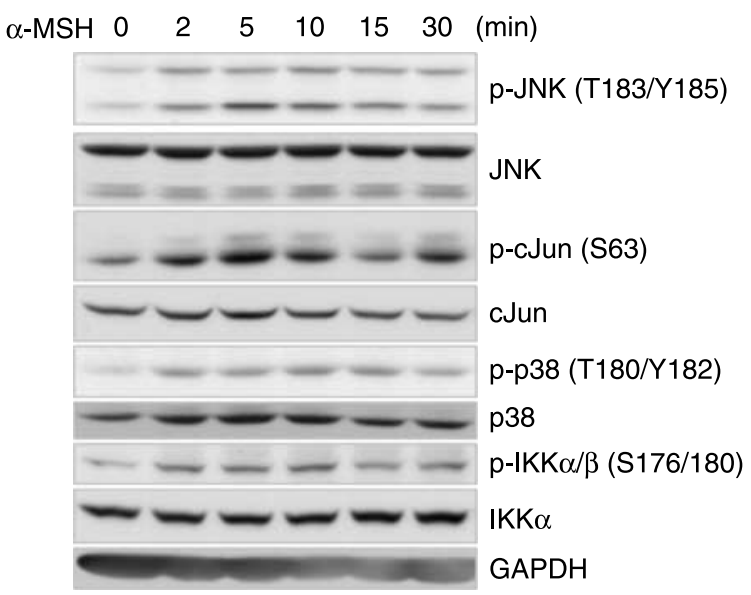

Figure 4 Phosphorylation of JNK, p38 MAPK, and IKK in response to $\alpha-\mathrm{MSH}$. Serum-starved (12 h) 3T3-L1 adipocytes were treated with $\alpha-\mathrm{MSH}(300 \mathrm{nM})$ for the indicated time periods. Whole-cell extracts were analyzed by western blots of phosphoJNK, phospho-cJUN, phospho-p38 kinases, and phospho-IKK protein. Equal loading of protein was checked by glyceraldehyde3-phosphate dehydrogenase (GAPDH) expression. Each experiment was performed independently at least three times.

of 3T3-L1 adipocytes immediately activated JNK, p38 MAPK, and IKK proteins in a time-dependent manner (Fig. 4). To determine whether elevation of intracellular cAMP is also necessary for $I l 6$ induction by $\alpha$-MSH, we used a pharmacological inhibitor of the cAMP signaling cascade. Pretreatment of 3T3-L1 adipocytes for 30 min with the PKA inhibitor H89 led to a reduction of the $\alpha$-MSH-induced increase in the level of 16 mRNA (Fig. 3D). Because H89 may also inhibit kinases other than PKA in the concentration range used here, we confirmed the involvement of PKA using the specific PKA activator 6-Bnz-cAMP, as well as other cAMP-elevating agents including forskolin, an activator of adenylyl cyclase, and isoproterenol, a $\beta$-adrenergic receptor agonist. Figure 3D shows that 6-Bnz-cAMP, forskolin, and isoproterenol mimicked the effect of $\alpha$-MSH on Il6 expression in 3T3-L1 adipocytes. Finally, we also observed these inhibitory effects on the IL6 release in a time-dependent manner (Fig. 3E). The same effects were observed in the ACTH-mediated $I l 6$ gene expression pattern (Fig. 5A-D). Taken together, these data indicate that PKA, p38 MAPK, JNK, and IKK mediated 166 production induced by $\alpha-\mathrm{MSH}$ or ACTH in 3T3-L1 adipocytes.

\section{Involvement of the MC5R in the $\alpha-M S H$-induced increase in $/ 16$ gene expression and MC2R in the ACTH-induced increase in $/ 16$ gene expression}

To investigate the role of the MC5R subtype in the $\alpha$-MSH-mediated increase in $I l 6$ production and of MC2R subtype in the ACTH-mediated increase in $I l 6$ production, we specifically inhibited MC5R expression by RNAi using a short interfering $M c 5 r$ RNA (siMC5R) and $M c 2 r$ RNA (siMC2R) in 3T3-L1 adipocytes (Fig. 6A and $\mathrm{C}$ ). Suppression of MC5R expression significantly attenuated the $\alpha$-MSH-induced increase in $I l 6$ mRNA level (Fig. 6B), and suppression of MC2R expression also significantly attenuated the ACTH-induced increase in Il6 mRNA level (Fig. 6D) in 3T3-L1 adipocytes. However, suppression of MC5R expression could not attenuate the ACTH-induced increase in $\mathrm{Il6}$ mRNA level, and suppression of MC2R expression could not attenuate $\alpha$-MSH-induced increase in $\mathrm{Il6}$ mRNA level (data not shown). These results suggest that MC5R is involved in the $\alpha-\mathrm{MSH}$-induced $\mathrm{Il} 6$ expression, and that MC2R is involved in the ACTHinduced $I l 6$ expression in 3T3-L1 adipocytes.

\section{Effect of $\alpha$-MSH on $1 / 6$ expression in primary fat tissue}

To investigate whether $\alpha$-MSH regulates $I l 6$ expression in primary fat tissue, the level of Il6 mRNA in epididymal fat pads was measured. Mice were i.v. injected with $\alpha-\mathrm{MSH}(1 \mathrm{mg} / \mathrm{kg})$ in the tail vein, and Il6 mRNA level in fat pads was measured at $0,1,3$, and $6 \mathrm{~h}$ after $\alpha$-MSH injection. $I l 6$ transcript level in fat pads peaked $1 \mathrm{~h}$ after injection and returned rapidly to the baseline by $6 \mathrm{~h}$ (Fig. 7), which correlated well with the profile of $\alpha$-MSH-induced $I l 6$ gene expression in 3T3-L1 adipocytes. These results suggest that MCRs function to trigger Il6 expression in response to $\alpha$-MSH in fat tissue.

\section{Discussion}

In contrast to the abundant data available on the classical roles of melanocortins in processes such as skin pigmentation, steroidogenesis, energy expenditure, and appetite regulation in the CNS (Cone 2006), little is known about the peripheral functions of melanocortins, particularly in the adipose tissues and in melanocortin interaction with adipocytokines. It has been reported that adipose tissues contribute as much as $35 \%$ of the basal circulating IL6. Moreover, there is a positive correlation between elevated IL6 and obesity and insulin resistance (Fernandez-Real \& Ricart 2003). Here, we further characterized IL6 as a newly described protein target of the melanocortin signaling pathway in adipocytes. Recently, other groups (Hoch et al. 2008, Iwen et al. 2008) reported that melanocortin induced Il6 gene expression, which was revealed by real-time quantitative RT-PCR analysis. In this study, we have demonstrated that melanocortins increase $I l 6$ gene expression and secretion through MCRs in 3T3-L1 adipocytes and mouse epididymal fat tissue. In addition, we have investigated knockdown effects on each MCR. These results suggest that $\alpha$-MSH-induced 

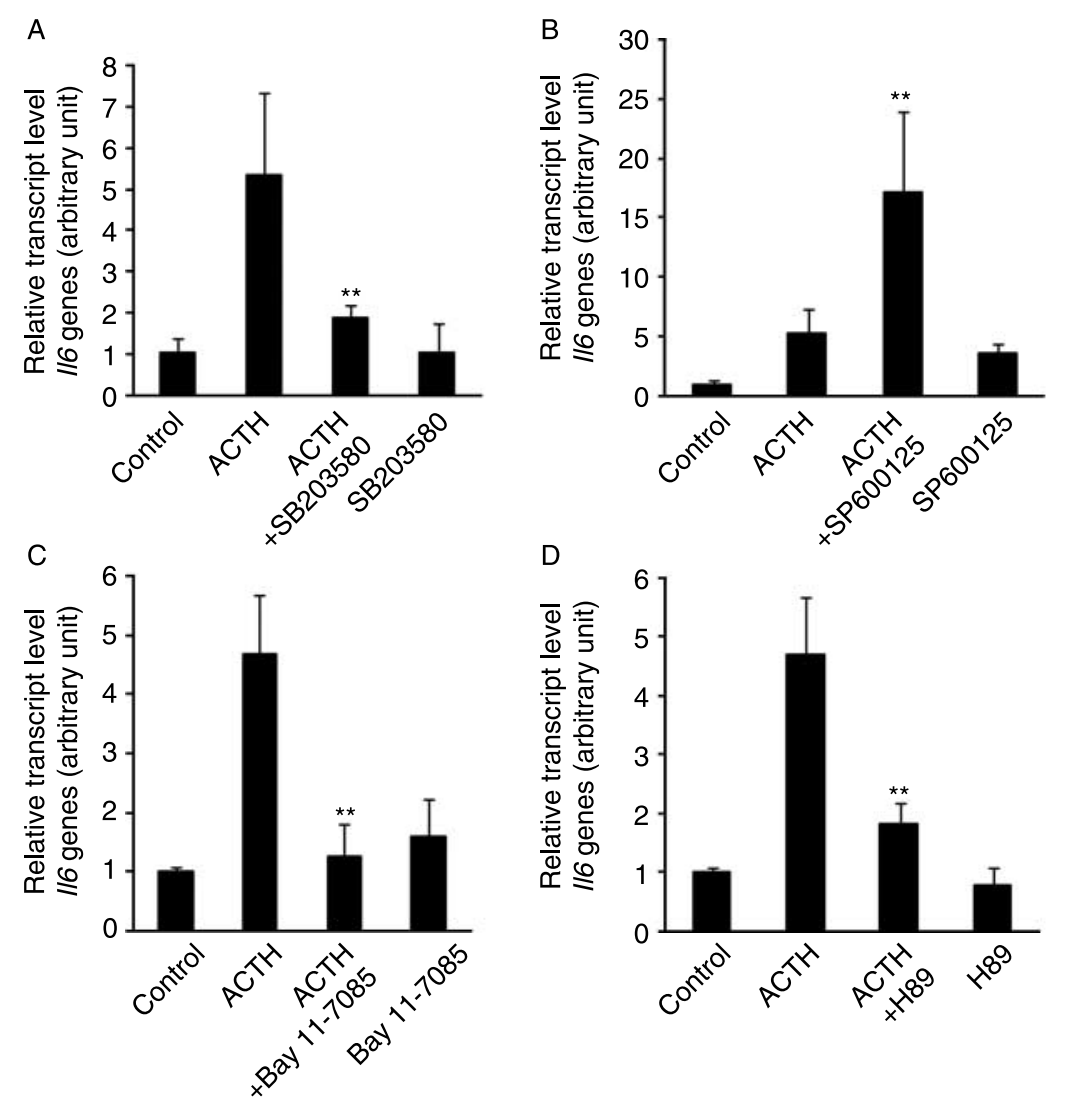

Figure 5 PKA, p38 MAPK, JNK, and IKK are involved in ACTH-induced $/ 16$ gene expression. Differentiated 3T3-L1 adipocytes were pretreated with A, SB203580 $(10 \mu \mathrm{M})$; B, SP600125 (10 $\mu \mathrm{M})$; C, Bay 11-7085 (10 $\mu \mathrm{M})$; and D, H89 $(1 \mu \mathrm{M})$ for 30 min prior to treatment with ACTH $(50 \mathrm{nM})$ for $1 \mathrm{~h}$. Data represent the means \pm s.D. of triplicate samples. ${ }^{\star} P<0.05 ;{ }^{\star} P<0.001$ compared with the ACTH-treated group. Each experiment was performed independently at least three times.

increase in $I l 6$ production is mainly mediated by MC5R, and that ACTH-induced increase in $I l 6$ production is mediated by MC2R. PKA, p38 MAPK, JNK, and IKK signaling pathways played important roles in the melanocortin-mediated $I l 6$ production.

We have demonstrated that the patterns of MCR expression in the 3T3-L1 adipocytes are in agreement with those of retroperitoneal, epididymal, and subcutaneous fat tissues. The differential expression profiles of five MCRs in 3T3-L1 cells have been reported (Norman et al. 2003). The expression pattern of MCRs has been analyzed with RT-PCR. We also performed RT-PCR and real-time quantitative RT-PCR. The analysis that was applied for the profile of MCRs was applied to mouse tissues. We found and confirmed that they expressed all types of MCRs by sequencing RT-PCR products, but of the five MCRs subtypes, MC2R and MC5R are expressed at the highest level in all adipose tissues. In addition to its role in the induction of IL6, described in this study, $\alpha$-MSH has a direct effect on lipid metabolism and leptin regulation
(Hoggard et al. 2004, Harmer et al. 2008). The observed effects of ACTH and $\alpha$-MSH on IL6 expression and secretion occur at concentrations similar to those that induce lipolysis and inhibit leptin expression in adipocytes. We have assumed that ACTH and $\alpha$-MSH act primarily on the MC2R and MC5R respectively (Cone 2006), since $\alpha$-MSH does not bind to MC2R and the hierarchical arrangement of melanocortins with regard to elevating intracellular cAMP level is evidenced for the functional expression of MC5R in 3T3-L1 adipocytes (Fig. 1C). Finally, the MC5R knockdown experiment confirmed the involvement of MC5R in $\alpha$-MSH-induced $I l 6$ production (Fig. 6B), and MC2R in ACTH-induced $I l 6$ production (Fig. 6D).

Widely considered a primary regulator of inflammation, p38 integrates inflammatory responses by regulating several aspects of target gene transcription and translation. p38 enhances both the transcriptional activity of NFKB via acetylation of p65 (Saha et al. 2007) and the translation of inflammatory cytokines, including IL6, via stabilization of their mRNAs by 

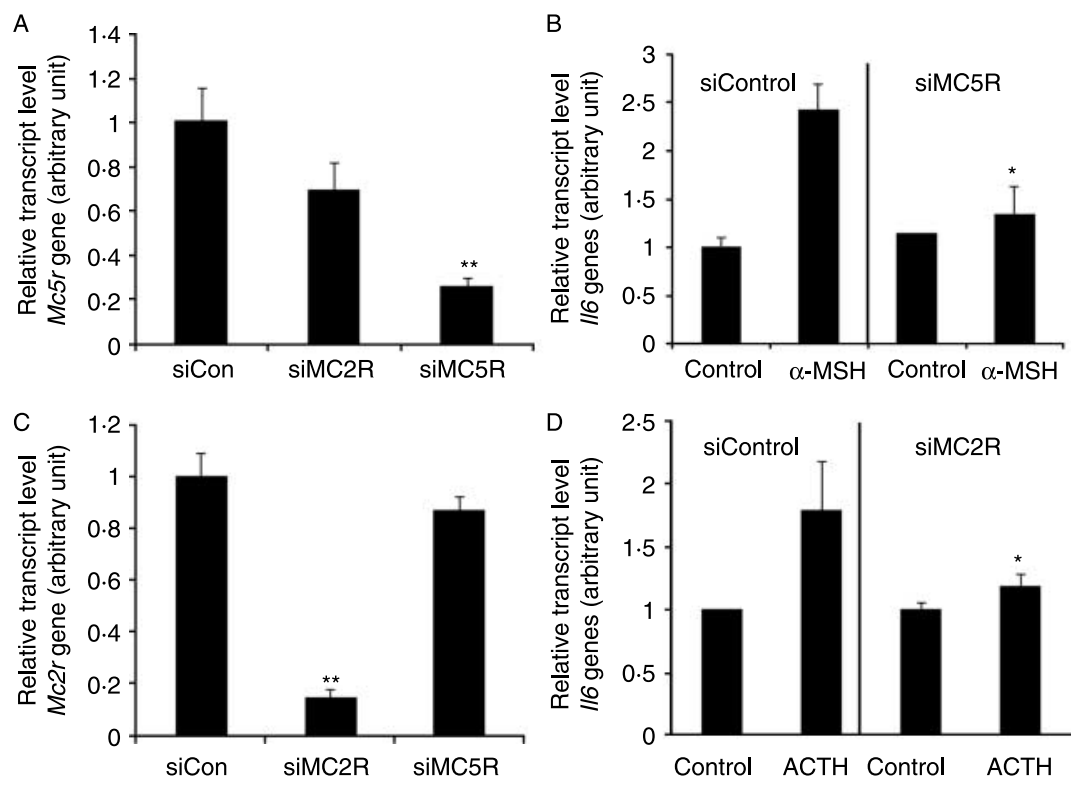

Figure $6 \alpha$-MSH increases $/ 16$ gene expression through MC5R, and ACTH increases II6 gene expression through MC2R. 3T3-L1 adipocytes were transfected for $48 \mathrm{~h}$ with siRNAs targeted to the MC5Rs (siMC5Rs), or scrambled control siRNAs (siControl), and transfected for $24 \mathrm{~h}$ with siRNAs targeted to the MC2Rs (siMC2Rs), or scrambled control siRNA (siControl). (A) The MC5R-specific siRNA reduced endogenous Mc5r expression as detected by real-time quantitative RT-PCR. Gapdh served as an internal control.

(B) 3T3-L1 adipocytes in which MC5R had been knocked down were stimulated with $\alpha$-MSH for $1 \mathrm{~h}$. $/ 16$ gene expression was evaluated by real-time quantitative RT-PCR. (C) The MC2R-specific siRNA reduced endogenous Mc2rexpression as detected by realtime quantitative RT-PCR. Gapdh served as an internal control. (D) 3T3-L1 adipocytes in which MC2R had been knocked down were stimulated with ACTH for $1 \mathrm{~h}$. I/6 gene expression was evaluated by real-time quantitative RT-PCR. Values represent the means \pm S.D. of triplicate samples. ${ }^{\star} P<0 \cdot 05 ;{ }^{\star \star} P<0.001$ compared with the siControltransfected group. Each experiment was performed independently at least three times.

phosphorylation of AU-rich element-binding proteins (Zhao et al. 2008). Because MCRs are coupled to adenylyl cyclase and several cAMP-elevating GPCR ligands such as prostaglandin E2, thyroid-stimulating hormone, and catecholamine have been shown to upregulate $I l 6$ mRNA expression in different cell lines (Mohamed-Ali et al. 2001, Liu et al. 2005, Antunes et al. 2006), it is reasonable to hypothesize that melanocortins activate $I l 6$ production in adipocytes. The cAMP signal transduction pathways can activate the exchange protein directly activated by cAMP (EPAC), which acts independently of PKA (Holz et al. 2006). However, a specific activator of EPAC (8-CPT-2'OMe-cAMP) did not induce IL6 secretion in adipocytes (data not shown), whereas a specific activator of PKA (6-Bnz-cAMP) potentiated $\alpha$-MSH-induced $I l 6$ expression (Fig. 3D). These data suggest that the PKA, but not the EPAC, pathway is involved in the melanocortin-induced $I l 6$ production in 3T3-L1 adipocytes.

In this study, we have described a novel proinflammatory role for MCRs in adipocytes. IKK/NFKB activation and JNK pathway are critical regulators of inflammation, and have been reported to be necessary for IL6 induction in many cells (Libermann \& Baltimore 1990, Tuyt et al. 1999, An et al. 2003). The induction of IL6 has been reported. The classical pathway of NFKB activation is controlled by the IKK complex. Activated IKK phosphorylates I $\mathrm{B}$, which is then ubiquitinated and rapidly degraded, allowing $\mathrm{NF} \kappa \mathrm{B}$ to translocate from the cytoplasm to the nucleus, where it activates gene transcription (Niederberger \& Geisslinger 2008). While the activation of the MCRs expressed in immune cells has been reported to have an anti-inflammatory effect, inhibiting $\mathrm{NF} \kappa \mathrm{B}$ activation and cytokine production induced by pro-inflammatory stimuli such as LPS (Yoon et al. 2003), our results nonetheless demonstrated that the activation of MCRs in the absence of another pro-inflammatory stimulus leads to the upregulation of $116 \mathrm{mRNA}$ and protein levels in adipocytes. JNK activation is also involved in the expression of IL6 in human monocytes (Tuyt et al. 1999), but $\alpha$-MSH-mediated JNK activation suppresses Il6 production in adipocytes as shown in Figs 3-5. It seems likely that adipocytes do not share the same regulatory pathways that have been identified in other cell types, such as immune cells. Moreover, recent 


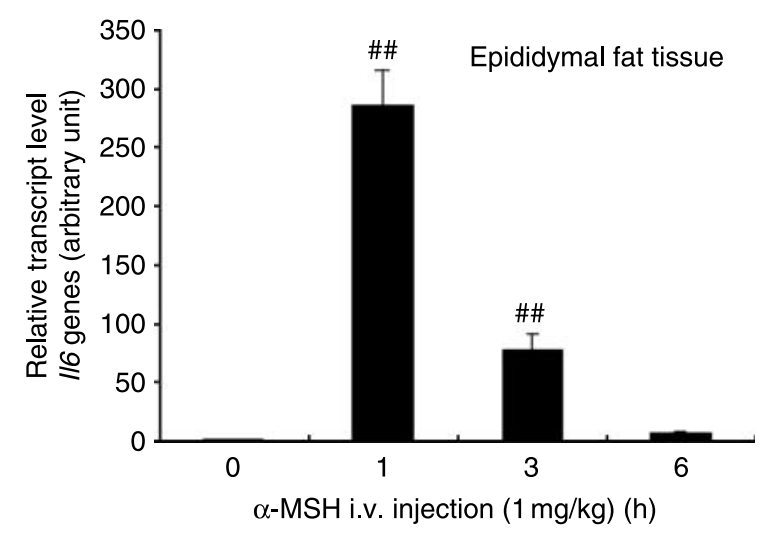

Figure 7 I.v. injection of $\alpha-\mathrm{MSH}$ induces $/ / 6$ gene expression in mouse epididymal fat tissue. Mice were i.v. injected via tail vein with $200 \mu \mathrm{l}$ sterile PBS containing $1 \mathrm{mg} / \mathrm{kg} \alpha-\mathrm{MSH}$. Epididymal fat tissue was collected at 1,3 , and $6 \mathrm{~h}$ after $\alpha$-MSH injection. I/6 transcript levels were determined by real-time quantitative RT-PCR. Values represent the means \pm s.D., $n=3$ for each time point. ${ }^{\# \#} P<0.001$ compared with the control group. Each experiment was performed independently at least three times.

studies on the IL6 promoter have demonstrated that induction of IL6 by several transcription factors including $\mathrm{C} / \mathrm{EBP} \alpha$, AP1, CREB, and NFKB occurs in a highly stimulus- or cell-specific manner (Fasshauer $e t$ al. 2003, Persson et al. 2005, Chen et al. 2006).

Since adipose tissue has recently been regarded as a fast-acting endocrine organ within the hierarchy of the hypothalamus and pituitary gland and because adipose tissue expresses specific receptors for pituitary hormones and hypothalamic releasing factors at both mRNA and protein levels (Schaffler et al. 2006), our findings provide further evidence of a significant interaction between adipocytokines and neuropeptides such as $\alpha-\mathrm{MSH}$ and ACTH. Our findings provide evidence for the existence of a hypothalamic-pituitary-adipose axis, and for the concept of 'adipotropins', which describe the roles of pituitary and hypothalamic hormones or releasing factors which directly target adipocytes via their specific receptors (Schaffler et al. 2006).

We have measured $I l 6$ expression level after injection of $1 \mathrm{mg} / \mathrm{kg}$ of $\alpha$-MSH. The concentration which we used is about $5 \mu \mathrm{M}$ per mouse approximately based on the blood volume which is about $6-8 \%$ of body weight. In most cases, the range from $200 \mu \mathrm{g} / \mathrm{kg}$ to $10 \mathrm{mg} / \mathrm{kg}$ for the concentration of $\alpha$-MSH is commonly used. The i.v. injection of $\alpha$-MSH increased $I l 6$ production as shown in Fig. 7. To confirm this, we administered an abdominal injection of $\alpha-\mathrm{MSH}$ of $1 \mathrm{mg} / \mathrm{kg}$, and showed similar results (data not shown). This result demonstrates that $\alpha-\mathrm{MSH}$ plays an important role in inducing Il6 expression in vivo.

The physiological relevance of melanocortin-induced Il6 production in adipose tissue remains unclear. However, pituitary melanocortins appear to have stress-related effects on adipocyte function. Brainderived $\alpha-\mathrm{MSH}$ is released during stress including immobilization stress (Khorram et al. 1985), and the melanocortinergic pathway is rapidly recruited under conditions of emotional stress (Liu et al. 2007). In addition, it has been suggested that in the case of ACTH- or $\alpha$-MSH-induced lipolysis in adipocytes, stressinduced lipolysis is mediated by pituitary release of melanocortins (Schaffler et al. 2006). Recently, human visceral and subcutaneous adipocytes have also been shown to express the corticotropin-releasing hormone receptor types 1 and 2, which play a major role in coordinating autonomic, cardiovascular, endocrine, and behavioral responses to stress (Seres et al. 2004). These data imply that adipose tissue may be a direct peripheral target organ of stress responses. On the other hand, recent studies have demonstrated that the production of IL6 can be directly stimulated by emotional depression and stressful experiences (Kiecolt-Glaser et al. 2003). In addition, circulating IL6 levels and secretion of IL6 from adipose tissue correlate with insulin resistance (Kristiansen \& Mandrup-Poulsen 2005). In this sense, our data suggest that IL6 could be a link between obesity, stress response, and insulin resistance.

To elucidate melanocortin's direct peripheral effects on adipocytes under conditions of stress, in vivo experiments addressing the role of melanocortin in the relationship between stress responses and insulin sensitivity are needed.

In summary, these studies provide direct evidence for peripheral action of melanocortins on $I l 6$ expression and production in adipocytes, and suggest that melanocortins may function as regulators of inflammation by regulating cytokine production. This is the first time that we find melanocortin-mediated $I l 6$ gene expression through adipocyte membrane receptors and signaling pathways through a knockdown experiment using siRNA and in vivo. In addition, our findings provide evidence for the existence of a regulatory loop between the HPA axis and circulating Il6.

\section{Declaration of interest}

The authors declare that there is no conflict of interest that could be perceived as prejudicing the impartiality of the research reported.

\section{Funding}

This work was supported by the National Research Foundation of Korea (NRF) grants (No. 20090063547 and No. 20090081464), Korea Science and Engineering Foundation (KOSEF) grants (No. M10641000077-08N4100-07710), Regional Core Research Program/ Anti-aging and Well-being Research Center and Brain Korea 21 program funded by the Korean Ministry of Education, Science and Technology. 


\section{References}

Ajuwon KM \& Spurlock ME 2005 Palmitate activates the NF-кB transcription factor and induces IL-6 and TNFalpha expression in 3T3-L1 adipocytes. Journal of Nutrition 135 1841-1846.

An J, Sun Y, Sun R \& Rettig MB 2003 Kaposi's sarcoma-associated herpesvirus encoded vFLIP induces cellular IL-6 expression: the role of the NF- $\mathrm{BB}$ and JNK/AP1 pathways. Oncogene 22 3371-3385.

An JJ, Rhee Y, Kim SH, Kim DM, Han DH, Hwang JH, Jin YJ, Cha BS, Baik JH, Lee WT et al. 2007 Peripheral effect of alpha-melanocytestimulating hormone on fatty acid oxidation in skeletal muscle. Journal of Biological Chemistry 282 2862-2870.

Antunes TT, Gagnon A, Chen B, Pacini F, Smith TJ \& Sorisky A 2006 Interleukin-6 release from human abdominal adipose cells is regulated by thyroid-stimulating hormone: effect of adipocyte differentiation and anatomic depot. American Journal of Physiology. Endocrinology and Metabolism 290 E1140-E1144.

Antunes TT, Gagnon A, Langille ML \& Sorisky A 2008 Thyroidstimulating hormone induces interleukin-6 release from human adipocytes through activation of the nuclear factor- $\kappa \mathrm{B}$ pathway. Endocrinology 149 3062-3066.

Bohm M, Luger TA, Tobin DJ \& Garcia-Borron JC 2006 Melanocortin receptor ligands: new horizons for skin biology and clinical dermatology. Journal of Investigative Dermatology 126 1966-1975.

Boston BA 1999 The role of melanocortins in adipocyte function. Annals of the New York Academy of Sciences 885 75-84.

Brown BL, Albano JD, Ekins RP \& Sgherzi AM 1971 A simple and sensitive saturation assay method for the measurement of adenosine $3^{\prime}: 5^{\prime}$-cyclic monophosphate. Biochemical Journal $121561-562$.

Butler AA, Marks DL, Fan W, Kuhn CM, Bartolome M \& Cone RD 2001 Melanocortin-4 receptor is required for acute homeostatic responses to increased dietary fat. Nature Neuroscience 4 605-611.

Chen W, Kelly MA, Opitz-Araya X, Thomas RE, Low MJ \& Cone RD 1997 Exocrine gland dysfunction in MC5-R-deficient mice: evidence for coordinated regulation of exocrine gland function by melanocortin peptides. Cell 91 789-798.

Chen BC, Liao CC, Hsu MJ, Liao YT, Lin CC, Sheu JR \& Lin CH 2006 Peptidoglycan-induced IL-6 production in RAW 264.7 macrophages is mediated by cyclooxygenase-2, PGE2/PGE4 receptors, protein kinase A, I kappa B kinase, and NF-кB. Journal of Immunology 177 681-693.

Cone RD 2006 Studies on the physiological functions of the melanocortin system. Endocrine Reviews 27 736-749.

Diya Z, Lili C, Shenglai L, Zhiyuan G \& Jie Y 2008 Lipopolysaccharide (LPS) of Porphyromonas gingivalis induces IL-1beta, TNF-alpha and IL-6 production by THP-1 cells in a way different from that of Escherichia coli LPS. Innate Immunity 14 99-107.

Fang X, Yu S, Bast RC, Liu S, Xu HJ, Hu SX, LaPushin R, Claret FX, Aggarwal BB, Lu Y et al. 2004 Mechanisms for lysophosphatidic acidinduced cytokine production in ovarian cancer cells. Journal of Biological Chemistry 279 9653-9661.

Fasshauer M, Kralisch S, Klier M, Lossner U, Bluher M, Klein J \& Paschke R 2003 Adiponectin gene expression and secretion is inhibited by interleukin-6 in 3T3-L1 adipocytes. Biochemical and Biophysical Research Communications 301 1045-1050.

Fernandez-Real JM \& Ricart W 2003 Insulin resistance and chronic cardiovascular inflammatory syndrome. Endocrine Reviews $\mathbf{2 4}$ 278-301.

Franchimont N, Durant D, Rydziel S \& Canalis E 1999 Platelet-derived growth factor induces interleukin-6 transcription in osteoblasts through the activator protein-1 complex and activating transcription factor-2. Journal of Biological Chemistry 274 6783-6789.

Fried SK, Bunkin DA \& Greenberg AS 1998 Omental and subcutaneous adipose tissues of obese subjects release interleukin6: depot difference and regulation by glucocorticoid. Journal of Clinical Endocrinology and Metabolism 83 847-850.
Gohil BC, Rosenblum LA, Coplan JD \& Kral JG 2001 Hypothalamicpituitary-adrenal axis function and the metabolic syndrome $\mathrm{X}$ of obesity. CNS Spectrums 6 581-586 (589).

Harmer SC, Pepper DJ, Cooke K, Bennett HP \& Bicknell AB 2008 Evidence of a possible role for Lys-gamma3-MSH in the regulation of adipocyte function. Journal of Endocrinology 196 149-158.

Hoch M, Hirzel E, Lindinger P, Eberle AN, Linscheid P, Martin I, Peters T \& Peterli R 2008 Weak functional coupling of the melanocortin-1 receptor expressed in human adipocytes. Journal of Receptors and Signal Transduction 28 485-504.

Hoggard N, Hunter L, Duncan JS \& Rayner DV 2004 Regulation of adipose tissue leptin secretion by alpha-melanocyte-stimulating hormone and agouti-related protein: further evidence of an interaction between leptin and the melanocortin signalling system. Journal of Molecular Endocrinology 32 145-153.

Holz GG, Kang G, Harbeck M, Roe MW \& Chepurny OG 2006 Cell physiology of cAMP sensor Epac. Journal of Physiology 577 5-15.

Iwen KA, Senyaman O, Schwartz A, Drenckhan M, Meier B, Hadaschik D \& Klein J 2008 Melanocortin crosstalk with adipose functions: ACTH directly induces insulin resistance, promotes a proinflammatory adipokine profile and stimulates UCP-1 in adipocytes. Journal of Endocrinology 196 465-472.

Jun DJ, Lee JH, Choi BH, Koh TK, Ha DC, Jeong MW \& Kim KT 2006 Sphingosine-1-phosphate modulates both lipolysis and leptin production in differentiated rat white adipocytes. Endocrinology 147 $5835-5844$

Kamimura D, Ishihara K \& Hirano T 2003 IL-6 signal transduction and its physiological roles: the signal orchestration model. Reviews of Physiology, Biochemistry and Pharmacology 149 1-38.

Kaufman D, Banerji MA, Shorman I, Smith EL, Coplan JD, Rosenblum LA \& Kral JG 2007 Early-life stress and the development of obesity and insulin resistance in juvenile bonnet macaques. Diabetes $\mathbf{5 6}$ $1382-1386$.

Khorram O, Bedran de Castro JC \& McCann SM 1985 Stress-induced secretion of alpha-melanocyte-stimulating hormone and its physiological role in modulating the secretion of prolactin and luteinizing hormone in the female rat. Endocrinology 117 2483-2489.

Kiecolt-Glaser JK, Preacher KJ, MacCallum RC, Atkinson C, Malarkey WB \& Glaser R 2003 Chronic stress and age-related increases in the proinflammatory cytokine IL-6. PNAS 100 9090-9095.

Kristiansen OP \& Mandrup-Poulsen T 2005 Interleukin-6 and diabetes: the good, the bad, or the indifferent? Diabetes $\mathbf{5 4}$ S114-S124.

Lagathu C, Bastard JP, Auclair M, Maachi M, Capeau J \& Caron M 2003 Chronic interleukin-6 (IL-6) treatment increased IL-6 secretion and induced insulin resistance in adipocyte: prevention by rosiglitazone. Biochemical and Biophysical Research Communications 311 372-379.

Legrand-Poels S, Schoonbroodt S \& Piette J 2000 Regulation of interleukin-6 gene expression by pro-inflammatory cytokines in a colon cancer cell line. Biochemical Journal 349 765-773.

Libermann TA \& Baltimore D 1990 Activation of interleukin-6 gene expression through the NF- $\mathrm{B}$ transcription factor. Molecular and Cellular Biology 10 2327-2334.

Liu XH, Kirschenbaum A, Yao S \& Levine AC 2005 Cross-talk between the interleukin- 6 and prostaglandin E(2) signaling systems results in enhancement of osteoclastogenesis through effects on the osteoprotegerin/receptor activator of nuclear factor-kB (RANK) ligand/RANK system. Endocrinology 146 1991-1998.

Liu J, Garza JC, Truong HV, Henschel J, Zhang W \& Lu XY 2007 The melanocortinergic pathway is rapidly recruited by emotional stress and contributes to stress-induced anorexia and anxiety-like behavior. Endocrinology 148 5531-5540.

Livak KJ \& Schmittgen TD 2001 Analysis of relative gene expression data using real-time quantitative PCR and the 2(-Delta Delta $C(\mathrm{~T}))$ method. Methods 25 402-408. 
Mohamed-Ali V, Goodrick S, Rawesh A, Katz DR, Miles JM, Yudkin JS, Klein S \& Coppack SW 1997 Subcutaneous adipose tissue releases interleukin-6, but not tumor necrosis factor-alpha, in vivo. Journal of Clinical Endocrinology and Metabolism 82 4196-4200.

Mohamed-Ali V, Flower L, Sethi J, Hotamisligil G, Gray R, Humphries SE, York DA \& Pinkney J 2001 B-Adrenergic regulation of IL-6 release from adipose tissue: in vivo and in vitro studies. Journal of Clinical Endocrinology and Metabolism 86 5864-5869.

Niederberger E \& Geisslinger G 2008 The IKK-NF-кB pathway: a source for novel molecular drug targets in pain therapy? FASEB Journal 22 3432-3442.

Norman D, Isidori AM, Frajese V, Caprio M, Chew SL, Grossman AB, Clark AJ, MichaelBesser G \& Fabbri A 2003 ACTH and alpha-MSH inhibit leptin expression and secretion in 3T3-L1 adipocytes: model for a central-peripheral melanocortin-leptin pathway. Molecular and Cellular Endocrinology 200 99-109.

Persson E, Voznesensky OS, Huang YF \& Lerner UH 2005 Increased expression of interleukin- 6 by vasoactive intestinal peptide is associated with regulation of CREB, AP-1 and C/EBP, but not $\mathrm{NF}-\kappa \mathrm{B}$, in mouse calvarial osteoblasts. Bone 37 513-529.

Rotter V, Nagaev I \& Smith U 2003 Interleukin-6 (IL-6) induces insulin resistance in 3T3-L1 adipocytes and is, like IL-8 and tumor necrosis factor-alpha, overexpressed in human fat cells from insulin-resistant subjects. Journal of Biological Chemistry 278 45777-45784.

Saha RN, Jana M \& Pahan K 2007 MAPK p38 regulates transcriptional activity of NF- $\mathrm{KB}$ in primary human astrocytes via acetylation of $\mathrm{p} 65$. Journal of Immunology 179 7101-7109.

Schaffler A, Scholmerich J \& Buechler C 2006 The role of 'adipotropins' and the clinical importance of a potential hypothalamic-pituitary-adipose axis. Nature Clinical Practice. Endocrinology and Metabolism 2 374-383.

Seres J, Bornstein SR, Seres P, Willenberg HS, Schulte KM, Scherbaum WA \& Ehrhart-Bornstein M 2004 Corticotropin-releasing hormone system in human adipose tissue. Journal of Clinical Endocrinology and Metabolism 89 965-970.

Shi H, Tzameli I, Bjorbaek C \& Flier JS 2004 Suppressor of cytokine signaling 3 is a physiological regulator of adipocyte insulin signaling. Journal of Biological Chemistry 279 34733-34740.
Tan KS, Nackley AG, Satterfield K, Maixner W, Diatchenko L \& Flood PM 2007 Beta2 adrenergic receptor activation stimulates proinflammatory cytokine production in macrophages via PKA- and NF-кB-independent mechanisms. Cellular Signalling 19 251-260.

Tang CH, Chiu YC, Tan TW, Yang RS \& Fu WM 2007 Adiponectin enhances IL-6 production in human synovial fibroblast via an AdipoR1 receptor, AMPK, p38, and NF-KB pathway. Journal of Immunology 179 5483-5492.

Tuyt LM, Dokter WH, Birkenkamp K, Koopmans SB, Lummen C, Kruijer W \& Vellenga E 1999 Extracellular-regulated kinase 1/2, Jun

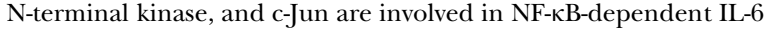
expression in human monocytes. Journal of Immunology 162 4893-4902.

Verhasselt V, Buelens C, Willems F, De Groote D, Haeffner-Cavaillon N \& Goldman M 1997 Bacterial lipopolysaccharide stimulates the production of cytokines and the expression of costimulatory molecules by human peripheral blood dendritic cells: evidence for a soluble CD14-dependent pathway. Journal of Immunology 158 2919-2925.

Wikberg JE \& Mutulis F 2008 Targeting melanocortin receptors: an approach to treat weight disorders and sexual dysfunction. Nature Reviews. Drug Discovery 7 307-323.

Yang YK \& Harmon CM 2003 Recent developments in our understanding of melanocortin system in the regulation of food intake. Obesity Reviews 4 239-248.

Yoon SW, Goh SH, Chun JS, Cho EW, Lee MK, Kim KL, Kim JJ, Kim CJ \& Poo H $2003 \alpha$-Melanocyte-stimulating hormone inhibits lipopolysaccharide-induced tumor necrosis factor-alpha production in leukocytes by modulating protein kinase A, p38 kinase, and nuclear factor $\mathrm{\kappa B}$ signaling pathways. Journal of Biological Chemistry 278 32914-32920.

Zhao W, Liu M \& Kirkwood KL 2008 p38alpha stabilizes interleukin-6 mRNA via multiple AU-rich elements. Journal of Biological Chemistry 283 1778-1785.

Received in final form 6 January 2010

Accepted 20 January 2010

Made available online as an Accepted Preprint 20 January 2010 